\title{
Reply to Dr. Ömer Yilmaz et al. with regard to a paper entitled "An endodermal cyst mimicking an intra-axial tumor in the medulla oblongata"
}

\author{
Jin Mo Cho $\cdot$ Jong Hee Chang
}

Received: 16 February 2011 / Accepted: 24 March 2011 /Published online: 9 April 2011

(C) Springer-Verlag 2011

Dear Editor,

We thank Yilmaz et al. for their interest in our article [1]. In their letter, Yilmaz et al. also reported one case of "multiple" endodermal cysts in the medulla oblongata, and they recommended observation, if the lesion is small and the patient has no symptom. We agree with them, but only partially for two reasons.

First of all, there was no pathologic diagnosis. The MR signal of endodermal cyst varies, depending on the content of a cyst $[2,3]$. Usually, the cyst wall is not enhanced, but it can sometimes be enhanced as demonstrated in our case [1]. Yilmaz et al. emphasized the rarity of their multiple endodermal cysts. However, the multiplicity, we think, could also suggest that they might not be endodermal cysts. Based on the findings of MR imaging they supplied, without the diffusion image, we rather think that the lesions could be another pathology such as an epidermoid cyst or other cystic lesions. For endodermal cysts, a radiological study cannot confirm the disease, and it is simply one of the tools for differential diagnosis.

Second, for most small and asymptomatic lesions, surgical removal is clearly unnecessary, and periodic radiologic follow-up is enough. However, if the cystic lesion causes symptoms or continues to grow, surgical intervention is unavoidable. In our paper, we did not recommend total resection for all cases regardless of the

J. M. Cho $\cdot$ J. H. Chang $(\bowtie)$

Department of Neurosurgery, Brain Research Institute,

Yonsei University College of Medicine,

134, Shinchon-dong, Sudaemoon-gu,

Seoul 120-752, Republic of Korea

e-mail: changjh@yuhs.ac location and surgical findings. However, considering the relatively higher risk of recurrence of this cyst, we should try to remove the cystic wall as much as possible. To avoid surgical morbidity and to determine the extent of resection, vigorous monitoring like motor evoked potential is essential. If the lesion cannot be completely removed, especially in a case of intramedullary location, shunting into the adjacent subarachnoid space could be considered for the prevention of reaccumulation of the cystic content. In that case, short-term imaging follow-up is needed [4]. As shown in our case [1], the cyst recurred in only 18 months after initial surgery and required a second surgery. We have carefully observed the residual cyst for a relatively short period of 5 years, and we believe the cyst has not recurred because of the radical excision in the second surgery.

Sincerely yours.

\section{References}

1. Cho JM, Ahn JY, Kim SH, Lee KS, Chang JH (2010) An endodermal cyst mimicking an intra-axial tumor in the medulla oblongata. Child's Nerv Syst 26:853-856

2. Preece MT, Osborn AG, Chin SS, Smirniotopoulos JG (2006) Intracranial neurenteric cysts: imaging and pathology spectrum. Am J Neuroradiol 27:1211-1216

3. Clare I, Kavar B, Dobie DP (2006) Neuroenteric cyst of the craniocervical junction. Australas Radiol 50:59-62

4. Mizuno J, Fiandaca MS, Nishio S, O’Brien MS (1988) Recurrent intramedullary enterogenous cyst of the cervical spinal cord. Child's Nerv Syst 4:47-49 